\title{
Design Review: A Teaching Tool for Project-based Learning
}

\section{Leandra Ramos, United States Military Academy}

Leandra Ramos is a Second Lieutenant in the U.S. Army Corps of Engineers and will report to her first duty station at Fort Drum, NY. She holds a BS degree in civil engineering from USMA (2021).

\section{Heather J. Yoshii, United States Military Academy \\ Kyle Beyer, United States Military Academy \\ Morgan R. Corliss, United States Military Academy \\ Lt. Col. Brad C. McCoy, United States Military Academy}

Brad C. McCoy is a Lieutenant Colonel in the U.S. Army, and currently an Asst. Professor in the Department of Civil and Mechanical Engineering and the Deputy Director of the Center for Innovation and Engineering at the U.S. Military Academy (USMA). He holds a BS degree in civil engineering from USMA (2001), and MS and PhD degrees in civil engineering from North Carolina State University (2011 and 2019). Brad is a licensed Professional Engineer (Missouri). His research interests include sustainable infrastructure development, sustainable construction materials, and engineering education.

\section{Col. Aaron T. Hill Jr., United States Military Academy}

Colonel Aaron Hill is an Assistant Professor and Design Group Director in the Department of Civil \& Mechanical Engineering at the United States Military Academy, West Point, New York. He holds a Bachelor of Science degree from West Point, a Master of Science degree in Engineering Management from Missouri S\&T, a Master of Science degree in Civil Engineering from Virginia Tech, and a PhD in Civil Engineering from The University of Texas at Austin. Aaron has served in the military for 23 years as an Engineer Officer with assignments around the world to include Afghanistan, Egypt, and BosniaHerzegovina. He is a licensed professional engineer in Virginia and a Project Management Professional. Aaron's primary areas of research are engineering education, the behavior of steel structures, and blast. Aaron mentors students by serving as an advisor for capstone projects and through service as an Officer Representative for Women's Volleyball and Men's Basketball. His passion for teaching and developing tomorrow's leaders resulted in his selection in 2009 for the American Society of Civil Engineers New Faculty Excellence in Teaching Award and the 2013 Outstanding Young Alumni Award for the Department of Civil and Environmental Engineering at Virginia Tech.

\section{Lt. Col. Kevin P. Arnett P.E., United States Military Academy}

LTC Kevin Arnett is a fifth year Assistant Professor at the US Military Academy. He received his B.S. in Civil Engineering from USMA in 2001, his M.S. Civil Engineering from U.C. Berkeley in 2011, and his PhD in Structural Engineering from UCSD in 2019. He teaches structural analysis and design of steel structures, and is a licensed Professional Engineer in California and Missouri. 


\title{
Design Review: A Teaching Tool for Project-Based Learning
}

\begin{abstract}
The stability of our nation's infrastructure depends on the precise work of educated engineers. How can we teach young, aspiring engineers the importance of reviewing each other's work before they enter this critical profession? This paper presents an evidence-based study of how applying a design review process to a project-based academic setting benefits engineering students and prepares them for successful careers. Specific objectives of the study were to generate conclusions regarding a design review's ability to (1) enhance learning opportunities for engineering students, (2) improve the effectiveness of a team whose members are of different engineering sub-disciplines, (3) improve the ability to communicate clearly and effectively with a range of audiences, and (4) improve the ability to solve complex engineering problems. The scope of this study includes the generation, implementation, and analysis of a design review process in capstone design projects during the 2020-21 academic year. The motivation for the study stems from evidence-based practices of applying a design review to other undergraduate civil engineering courses. Existing studies indicate that a design review process within typical engineering courses reduced homework errors, improved student grades, increased student learning, and developed students' ability to communicate clearly and effectively. However, these existing studies do not address project-based learning environments. A capstone design course requires a team of student engineers to research, design, build, and test an engineering solution to address a real-world problem, often with an existing client. The capstone design review process presented in this study was formatted to allow the process to be exportable to projects of varying scope and team size. The design review consisted of project teammates pairing up and independently reviewing each other's products. The review itself required partners to answer a set of questions about each other's work to ensure each member of the team was fulfilling their team role and contributing clear, complete, and correct work. Partners also provided each other overall product feedback and recommendations, and designers were able to reflect on their partner's feedback and adjust their products before submitting them to the project client. This design review was an iterative process that occurred throughout the design process of three capstone team projects. The effectiveness of the design review was determined through the performance and quality of assignments established by the project advisors as well as the final project and presentation. Through likert scale questions and open-ended feedback, it was found that students believed their learning was enhanced and they gained a deeper understanding across all aspects of their project. Students also felt that they were able to interact more and learn from their teammates, therefore fostering team effectiveness. Students noted that preparing their products for a teammate to review forced them to ensure that their work was clear and understandable, and they became more confident about the process of reviewing other's work and having their work reviewed, which is a key factor in their future success in solving complex engineering problems. Finally, advisors noted improved quality of project submissions.
\end{abstract}




\section{Introduction}

It is critical for engineering students to know the importance of reviewing each other's work before entering the engineering profession. This paper presents an evidence-based study on a design review's ability to (1) enhance learning opportunities for engineering students, (2) improve the effectiveness of a team whose members are of different engineering sub-disciplines, (3) improve the ability to communicate clearly and effectively with a range of audiences, and (4) improve the ability to solve complex engineering problems. In this context, complex engineering problems can be defined as "complex, ill-formed, and open-ended problems which fosters flexible thinking and supports intrinsic motivation" [1]. Additional outcomes of the study included identifying plans for future design review iterations. This study encompasses the generation, implementation, and analysis of the design review process in three capstone design projects within an undergraduate civil engineering program during the 2020 academic year. These projects were compared to eight capstone projects that did not implement a design review process. It was hypothesized that a design review would improve team effectiveness as well as enhance student learning, communication, and engineering problem-solving.

First, this paper summarizes literature about four areas of concern - team effectiveness, student learning, communication, and engineering problem-solving-then provides details about how the implementation of design review into project-based learning (PBL) addresses the aforementioned. Data gathered for analysis in this project included (1) likert scale question feedback, (2) open-ended student feedback, and (3) Comprehensive Assessment of Team Member Effectiveness (CATME) survey results. Conclusions from the analysis are described, and ideas to improve the implementation of the design review process in future semesters are summarized.

\section{Background}

The current state of engineering education across the four areas of concern within the study is summarized below.

\section{The Student Learning Problem}

An engineering project requires subject matter experts to contribute to different aspects of the design. During PBL, students assume specific roles on the team, and these teammates inevitably become subject matter experts within their roles. Design review then forces teammates to learn and understand each other's job and contribution to the project. Some capstone design projects are multidisciplinary with students from across multiple majors and multiple departments. The design review process gives students the opportunity to learn about their project from a different engineering perspective, consequently growing their breadth of knowledge. The University of South Carolina's Department of Mechanical Engineering studied the impact that "mechatronics" has on engineering education [2]. Victor Giurgiutiu et al. define mechatronics as an academic discipline that combines the fields of mechanical engineering, electrical engineering, computer engineering, and information technology. They state that the goal of mechatronics is to "develop in our students the right blend of technical knowledge, scientific tools, and communication skills" so that students are prepared to face the design, analysis, and manufacturing challenges 
that their future employers will present them. According to the article, engineering students should be informed in many facets of engineering to meet and optimize a project's quality, time, and cost requirements upon graduation. The study found that mechatronic courses benefit faculty, undergraduate students, and graduate students. Design review implements the approach taken in mechatronics by encouraging students to understand the different academic disciplines of their project, which enhances student learning.

In the past, the influence of design review was studied at the United States Military Academy as a formal requirement in a civil engineering course [3]. This design review required students to pair up with a peer in their class to check each other's homework prior to submitting the homework individually. The article noted that the expectation was for students to annotate mistakes they found or disagreements they had about the work, and to discuss the error or misunderstanding with each other before submission. This allowed students to look back at and explain their completed work and fix any unclear points or mistakes [3]. Through likert scale questions, it was found that 36 out of 48 students either agreed or strongly agreed that the design review increased their learning and knowledge of the material. Moreover, 44 out of 48 students either agreed or strongly agreed that the design review helped correct mistakes that boosted their grades and contributed to their learning. The author directly saw test and homework grades rise, increasing the overall course average from $85 \%$ the previous year to $86.4 \%$. Considering these results, a design review implemented into a PBL course will likely enhance student learning across a range of engineering disciplines. Enhancing student learning will likely improve project quality and leave engineering students feeling better prepared to take on future projects as certified engineers.

\section{The Team Effectiveness Problem}

Design review improves team effectiveness because it offers extra time for the team to come together and ensure each team member understands the objectives, results, and conclusions of all team members. Further design review provides an opportunity to correct misunderstandings across the team that detract from the overall team's success. When team members have separate focuses, there must be an intentional assembly to see how it will all affect the big picture of the project. The largest competency gap between expectations of students with engineering degrees and their experience with new graduates was in the arena of teamwork, specifically understanding diversity, team building, and teamwork skills [6]. Design review offers the ability for engineering students to develop their teamwork skills by working with one another to improve their projects. With the aspect of working towards a larger, final project, design reviews have shown that students come to trust the advice and value the guidance of their peers [7]. By reviewing a partner's work, it allows them to talk more about their objectives and how they affect the larger picture. In a classroom environment, it would be effective to perform a design review with a new partner for each assignment to encourage communication with a wider range of peers [3].

Working with new partners can be an effective way to increase teamwork skills with new people, but in a PBL environment, each member of the team has their own focus and should work with those in the team with a similar scope. For a PBL environment, pairings for design review should have similar areas of focus so teams already have a general understanding of what they are reviewing [9]. Grouping team members in their focus areas or areas of expertise facilitates 
effective communication between design review partners because both parties are aware of the work being done. If a team member who lacks understanding on a topic were to conduct the design review, it could create an imbalance of teamwork and become a one-sided conversation, rather than the two-way collaborative discussion that is desired in an effective design review process. While it can be a challenge to develop effective programs that will allow engineering faculty to teach engineering team development skills in their courses [6], PBL offers the ability for teams to rely on one another to accomplish engineering objectives and successfully solve complex problems. In the classroom, a student does not necessarily have to work with others to perform well, but in a group project, the team must work together effectively to get the results they desire. Enforcing design review amongst PBL teams will increase the development of their teamwork skills by working through problems and discussing at a high level.

\section{The Communication Problem}

Design review enhances communication skills by encouraging peers to fully comprehend each other's work. The designer must ensure that their products are clear and understandable before presenting them to the reviewer. Employers and engineering societies consider communication skills as a vital element of a modern engineer's skill set [4]. The communication of work is just as important as the work itself because many times the presentation of the work will be intended for stakeholders who lack technical understanding of the specific work that is being done. After interviews with professionals in the field, Ann Darling and Deanna Dannels explained that technical people generally are not strong communicators, which is an issue because technical workers must interface with clientele [5]. The ability to present completed work to a nontechnical audience of stakeholders is vitally important for everyone involved such that clients fully understand what they are paying for.

Not only should engineers be able to communicate their plans effectively with stakeholders, but they should also be able to communicate with other engineers within the discipline. Edward Gehringer mentions that design review gives students the experience in communicating with the kinds of audiences they will need to write for on the job after graduation. By doing so, engineers will show a stronger breadth of knowledge across their discipline [9]. An Engineering Curriculum Task Force study identified "effectiveness in communicating ideas" as more important than mathematics, science, and technical skills in the professional life of an engineer [5]. By reviewing the work done, a student can ask questions about unclear work in the initial draft, emphasizing to the designer where clarifying language is needed to support the presented results and conclusions or to clearly articulate the desired end-state of the work. In the article "Integrating Written Communication Skills in Engineering Education," author Marc Riemer stated that writing about previous work not only strengthens critical thinking and problemsolving skills but that it allows engineers to recognize and address personal errors [4]. Writing allows for the ability to come together, understand where there are misunderstandings in the work, and fix any errors before they have the chance to affect anyone. Misinterpretation, inefficiency, and wasted time due to ineffective or poor communication negatively impacts problem resolution [4]. Design review will give peers the ability to read each other's work to ensure they communicate their work effectively. 


\section{The Engineering Problem}

Design review aids in one's ability to solve complex engineering problems because it promotes the sharing of ideas among peers and allows for designs to be evaluated from an outside perspective. Engineers are often tasked with solving complex problems but rarely work alone in the process. While portioning out different parts of the problem may intrinsically seem more efficient, this also diminishes the team's ability to work with one another. Design review conducted at the peer level develops students' social skills, fosters mature behaviors, and increases higher-order thinking [7]. This not only helps students through the engineering design process, but also gives them skills applicable to other aspects of life. The manner of thinking in the engineer design process can be easily applied to complex problem-solving. Complex problem-solving, defined as "thinking that occurs to overcome barriers between a given state and a desired goal state by means of behavioral and/or cognitive, multistep activities" is an important tool for facing difficult problems [8]. Utilizing design review to refine one's engineering design process increases complex problem-solving capabilities.

The engineering design process consists of five steps [10]. First, engineers must formulate the problem and identify tasks to be investigated and completed. The second step is to generate multiple alternative conceptual designs. Then, the benefits and drawbacks are found for each of the conceptual designs through many levels of analysis and evaluation. Next, the detailed design is chosen, and issues of implementation are investigated. Lastly, once the design is ready, implementation can begin by building and testing the prototype. Each step has unique tools and techniques associated. The iterative nature of the design review process allows students to reflect and improve the project at multiple phases. It fosters a deeper understanding of the design and generates a level of tangible growth that students can see throughout the engineering design process [10].

\section{Research Significance}

The objective of this study is to generate conclusions regarding a design review's ability to (1) enhance learning opportunities for engineering students, (2) improve the effectiveness of a team whose members are of different engineering sub-disciplines, (3) improve the ability to communicate clearly and effectively with a range of audiences, and (4) improve the ability to solve complex engineering problems. Given the current state of engineering education across these four areas of concern, a design review process will likely enhance student learning across a range of engineering disciplines, give peers the ability to read each other's work to ensure they communicate their work effectively, increase the development of teamwork skills by working through problems and discussing at a high level, and allow students to reflect and improve the project at multiple phases, and foster a deeper understanding of the design. If a design review process achieves these goals, engineering students will be better prepared for successful careers.

\section{Implementation}

Design review was implemented into three capstone design project teams: ASCE Concrete Canoe Competition, AISC Steel Bridge Competition, and US Army Corps of Engineers 
(USACE) Lock and Dam Design Standardization. Each project team completed in-progress reviews (IPR) with their advisors as a graded requirement. An IPR consisted of a presentation that showed project progress to-date and was used to ensure the team was on track to complete the project on time, to ensure the work was clear and correct, and to confirm the team's ability to present their work to a mixed audience of technical and non-technical client representatives. Before the first IPR, each project team was introduced to the design review packet, which can be found in the Appendix. The implementation of the design review process is described below:

1) Each team member will identify their "role" or "job" within the team. This role represents their engineering sub-discipline. Examples include Project Manager, Fabrication Specialist, Concrete Mix Design Engineer, etc.

2) Each member of the team will partner up with a teammate. Partner A will be Partner B's reviewer and vice versa.

3) The partners will consider each other's roles on the team. Partner A may ask themself, "What is Partner B working on? What should Partner B know about the project?" Partner A will then come up with a set of questions (at least 5) to ask Partner B that will provide them with an in-depth analysis of Partner B's work. These questions will be written on page 2 of Partner A's design review packet as seen in the Appendix. Partner B will complete the same process on their own design review packet.

4) The partners will give each other their current products in a form that best showcases their work so far on the project. Examples include a typed summary, SolidWorks, Excel, MS Project, etc. The products should be complete and easy to follow for the reviewer.

5) After the partners receive each other's products, they will independently conduct a design review of their partner's work. The partners must conduct this step by themselves and they may not contact each other in any way. Partner A will attempt to thoroughly answer each of the questions they wrote in step 3. If Partner A cannot answer a question, they will articulate this next to the question on page 2. If Partner A is unsure of or confused about something in Partner B's work, Partner A will comment about it on page 3 of their design review packet. Partner A will provide any recommendations they have about Partner B's work on page 3 of their design review packet. Partner B will complete the same process.

6) After the partners are complete with the design reviews, they will sit down and discuss each other's reviews. They will discuss any unanswered questions and clarify any points of confusion or recommendations.

7) Partner A will switch design review packets with Partner B and respond to the questions, comments, concerns, and recommendations on page 3 of Partner B's packet. Partner A will adjust their initial product based on the design review conducted by Partner B. After adjustments are complete, Partner A and Partner B will sign the document on page 3 to signify that the design review was completed using their best work and judgment as engineers. Partner B will complete the same process with Partner A's packet. Partner A will keep the design review packet Partner B completed, and Partner B will keep the design review packet Partner A completed.

8) The design reviews are submitted or presented based on the instructor's/advisor's guidance. In this study, the students kept their design review packets to reflect on how the process influenced their IPR performance. 


\section{Results}

At the end of the first semester, student feedback was collected via two surveys - one from the three capstone design project teams that implemented the design review process and one from the eight capstone design project teams that did not implement the design review process. For those capstone design teams that implemented the design review process, all 16 students from across the three capstone design teams completed the survey. The concrete canoe team consisted of four civil engineering students, the steel bridge team consisted of five civil engineering students and one system engineering student, and the USACE lock and dam team consisted of six civil engineering students.

The authors had access to all 16 of the student responses to likert scale questions. The following likert scale was used for each question: 5 - strongly agree, 4 - agree, 3 - neither agree nor disagree, 2 -disagree, and 1 - strongly disagree). Additionally, each student could provide openended comments with the survey responses.

The likert scale questions on the feedback survey were as follows:

1) Design review enhanced your learning opportunities by reviewing the work of a teammate, requiring you to explain your own work, and requiring you to understand the work of another engineering major or sub-discipline.

2) Design review improved the effectiveness of your team whose members are of different engineering majors or whose members adopted roles of different engineering subdisciplines.

3) Design review improved your ability to communicate clearly and effectively with an audience not familiar with your work.

4) Design review improved your ability to solve complex engineering problems by requiring you to respond to your reviewer's comments and adjust your product.

The responses to each of the four questions are shown in Table I.

TABLE I

LIKERT SCALE FEEDBACK: DESIGN REVIEW TEAMS

\begin{tabular}{|c|c|c|c|}
\hline Question & $\begin{array}{c}\text { Agreed or Strongly } \\
\text { Agreed }\end{array}$ & Neutral & Disagreed \\
\hline $\mathbf{1}$ & 14 & 0 & 1 \\
\hline $\mathbf{2}$ & 9 & 6 & 1 \\
\hline $\mathbf{3}$ & 15 & 0 & 1 \\
\hline $\mathbf{4}$ & 14 & 1 & 1 \\
\hline
\end{tabular}

Open-ended comments supported the results of the likert scale questions. An excerpt of the comments is provided below.

1) Reviewing the work of my teammate gave me a better catch on how the project works overall and what could be changed by giving a different perspective.

2) As a team that has split up roles, it is good to see really how much the other group has been working on to come as a whole. 
3) It gave all members a greater understanding of the scope of the project and allowed for better communication about the intricacies of the design to someone unfamiliar with the project.

4) When a comment was made on my work, I tried even harder to fix that issue and it forced me to look over everything again to make sure there weren't more errors that didn't get picked up.

Student feedback was collected from the eight other capstone design project teams who did not implement a design review in their engineering design process. The likert scale questions included:

1) Design review would have enhanced your learning opportunities by reviewing the work of a teammate, requiring you to explain your own work, and requiring you to understand the work of another engineering major or team member who adopted the role of a different engineering sub-discipline (e.g., Project manager, Concrete Mix Engineer, Fabrication Specialist...).

2) Design review would have improved the effectiveness of your team whose members are of different engineering majors or whose members adopted roles of different engineering sub-disciplines (e.g., Project manager, Concrete Mix Engineer, Fabrication Specialist...).

3) Design review would have improved your ability to communicate clearly and effectively with an audience not familiar with your work.

4) Design review would have improved your ability to solve complex engineering problems by requiring you to respond to a reviewer's questions, comments, concerns, and recommendations and adjust your work based on their feedback.

The responses to each of the four questions are shown in Table II.

TABLE II

LIKERT SCALE FEEDBACK: NON-DESIGN REVIEW TEAMS

\begin{tabular}{|c|c|c|c|}
\hline Question & $\begin{array}{c}\text { Agreed or Strongly } \\
\text { Agreed }\end{array}$ & Neutral & Disagreed \\
\hline $\mathbf{1}$ & 28 & 4 & 2 \\
\hline $\mathbf{2}$ & 26 & 8 & 1 \\
\hline $\mathbf{3}$ & 27 & 8 & 0 \\
\hline $\mathbf{4}$ & 30 & 5 & 0 \\
\hline
\end{tabular}

Results from an End-of-Course-Survey taken by each member of every capstone team were collected. The available responses to these questions were also based on a likert scale (5 was strongly agree, 4 was agree, 3 was neutral, 2 was disagree, and 1 was strongly disagree). Questions included:

1) In this course, my ability to think creatively and take intellectual risks increased.,

2) In this course, my critical thinking ability increased.

3) My fellow students contributed to my learning in this course.

4) My instructor helped me to understand the importance and practical significance of this course.

5) My motivation to learn and to continue learning has increased because of this course. 
6) My personal schedule allows me enough time to adequately prepare for my optimum academic performance.

7) My personal schedule allows me enough time to reflect on the material I have learned in class.

8) The homework assignments, papers, and projects in this course could be completed within the time guideline of a 2:1 ratio of out-of-class time versus in-class time.

Average responses to questions 1 through 8 are presented in Table III.

TABLE III

END OF COURSE SURVEY RESULTS

\begin{tabular}{|c|c|c|c|c|c|c|c|c|}
\hline Question & $\mathbf{1}$ & $\mathbf{2}$ & $\mathbf{3}$ & $\mathbf{4}$ & $\mathbf{5}$ & $\mathbf{6}$ & $\mathbf{7}$ & $\mathbf{8}$ \\
\hline Average response & 4.6 & 4.8 & 4.7 & 4.5 & 4.7 & 4.1 & 4.1 & 3.9 \\
\hline
\end{tabular}

Lastly, results from the CATME peer survey were collected. All capstone design project teams completed the survey at the end of the semester. "The CATME Peer Evaluation describes behavior typical of various levels of performance," and team members were required to "select the category of behaviors that most closely matches the behavior of each student on their team (including themselves)" [11]. Behaviors associated with a rating of 5 are characterized as being effective and hard-working. The rating decreases down to 1, where behaviors are characterized as being apathetic or careless. Tables IV-VII summarize the average results of the three capstone design teams with design review and the eight capstone design teams without design review.

TABLE IV

CAPSTONES WITH DESIGN REVIEW

\begin{tabular}{|c|c|c|c|c|}
\hline & \multicolumn{3}{|c|}{ Average Peer Rating } & \\
\hline Behavior & CC & Team 2 & Team 3 & Average \\
\hline Contributing to the team's work & 4.2 & 3.9 & 4.2 & $\mathbf{4 . 1}$ \\
\hline Interacting with teammates & 4.3 & 4.0 & 4.8 & $\mathbf{4 . 4}$ \\
\hline Keeping the team on track & 4.1 & 3.8 & 4.3 & $\mathbf{4 . 1}$ \\
\hline Expecting quality & 4.1 & 4.0 & 4.6 & $\mathbf{4 . 2}$ \\
\hline $\begin{array}{c}\text { Having related knowledge, } \\
\text { skills, and abilities }\end{array}$ & 4.3 & 3.9 & 4.5 & $\mathbf{4 . 2}$ \\
\hline
\end{tabular}

TABLE V

CAPSTONES WITHOUT DESIGN REVIEW

\begin{tabular}{|c|c|c|c|c|c|c|c|c|c|}
\hline & \multicolumn{7}{|c|}{ Average Peer Rating } & \\
\hline Behavior & $\mathbf{1}$ & $\mathbf{2}$ & $\mathbf{3}$ & $\mathbf{4}$ & $\mathbf{5}$ & $\mathbf{6}$ & $\mathbf{7}$ & $\mathbf{8}$ & Average \\
\hline Contributing to the team's work & 4.6 & 4.0 & 4.4 & 3.8 & 4.0 & 3.0 & 4.5 & 4.5 & $\mathbf{4 . 1}$ \\
\hline Interacting with teammates & 4.4 & 4.0 & 4.4 & 3.9 & 4.0 & 3.0 & 4.8 & 4.3 & $\mathbf{4 . 1}$ \\
\hline Keeping the team on track & 4.3 & 4.0 & 4.3 & 3.7 & 4.0 & 4.0 & 3.5 & 4.3 & $\mathbf{4 . 0}$ \\
\hline Expecting quality & 4.6 & 3.6 & 4.3 & 3.9 & 4.0 & 4.0 & 4.5 & 4.0 & $\mathbf{4 . 1}$ \\
\hline $\begin{array}{c}\text { Having related knowledge, skills, } \\
\text { and abilities }\end{array}$ & 4.7 & 4.0 & 4.4 & 4.2 & 4.0 & 3.0 & 4.8 & 4.3 & $\mathbf{4 . 2}$ \\
\hline
\end{tabular}


TABLE VI

CAPSTONES WITH DESIGN REVIEW

\begin{tabular}{|l|c|c|c|c|}
\hline & \multicolumn{3}{|c|}{ Average Peer Rating } & \\
\hline \multicolumn{1}{|c|}{ Behavior } & CC & Team 2 & Team 3 & Average \\
\hline Task commitment & 4.1 & 4.3 & 4.6 & $\mathbf{4 . 3}$ \\
\hline Task attraction & 4.3 & 3.5 & 4.6 & $\mathbf{4 . 1}$ \\
\hline Interpersonal cohesiveness & 4.3 & 4.5 & 4.3 & $\mathbf{4 . 4}$ \\
\hline
\end{tabular}

TABLE VII

CAPSTONES WITHOUT DESIGN REVIEW

\begin{tabular}{|l|c|c|c|c|c|c|c|c|c|}
\hline & \multicolumn{7}{|c|}{ Average Peer Rating } & \\
\hline \multicolumn{1}{|c|}{ Behavior } & $\mathbf{1}$ & $\mathbf{2}$ & $\mathbf{3}$ & $\mathbf{4}$ & $\mathbf{5}$ & $\mathbf{6}$ & $\mathbf{7}$ & $\mathbf{8}$ & Average \\
\hline Task commitment & 4.2 & 4.3 & 4.3 & 4.6 & 4.0 & 4.7 & 4.8 & 3.8 & $\mathbf{4 . 3}$ \\
\hline Task attraction & 4.1 & 4.1 & 4.6 & 4.1 & 4.7 & 4.7 & 4.3 & 3.3 & $\mathbf{4 . 2}$ \\
\hline Interpersonal cohesiveness & 3.6 & 3.4 & 4.5 & 4.1 & 4.7 & 4.7 & 3.8 & 4.2 & $\mathbf{4 . 1}$ \\
\hline
\end{tabular}

*Task commitment includes: Our team is united in trying to reach its goals for performance, I'm unhappy with my team's level of commitment to the task [scale reversed], and our team members have conflicting aspirations for the team's performance [scale reversed].

Task attraction includes: Being part of the team allows team members to do enjoyable work, team members get to participate in enjoyable activities, team members like the work that the group does.

Interpersonal cohesiveness includes: Team members like each other, team members get along well, team members enjoy spending time together.

\section{Analysis}

Based on the feedback received from both surveys, the results were consistent with the existing literature that the team reviewed before implementing design review into their capstone teams. The greatest impact design review had on each of the capstone teams was that the design review process offered them the ability to communicate clearly and effectively with an audience not familiar with their work. One of the goals of design review is that team members are communicating clearly to the point where a person in one role can understand and review the work done by another. Not only did design review assist in pushing students to improve their communication skills as engineers, but that communication also proved to enhance their learning opportunities by sitting down with someone with a different role and either explaining their work to someone within a different discipline or learning about a different discipline entirely. It was also clear from the results that the team progressed on their ability to solve complex engineering problems because design review pushed them to review the comments that their teammates had for their work and allowed them a second opportunity to solve the complex problems offered in the capstone design project environment. The capstone teams also understood how design review was able to bring together members of the team in different majors or sub-disciplines. Many of the projects incorporate interdisciplinary learning so that their products can use the skills of others where they may not have the most experience. By conducting design review in these 
projects, it challenges those to review each other's work outside of their own disciplines and understand the contributions made by everyone on the team. All 11 capstone design teams, regardless of the use of the design review process had very similar opinions that design review can make a significantly positive impact on the outcomes in a project-based learning environment.

Based on the results from the CATME Peer Evaluation, there were some differences between the teams that implemented the design review process and those that did not. The first difference was interacting with teammates. This category focused on how the team worked together and ensured that all members contributed to the outcome. The group members who conducted design review had an average of 4.4 for interacting with teammates whereas the members who did not conduct design review had an average of 4.1. While this is not a large difference, it does indicate the extra work that was included with performing design review improved team effectiveness and teamwork. Another CATME Peer Evaluation category in which design review teammates scored higher than those who did not implement the design review was interpersonal cohesiveness. This category focused on individual interactions within each team both in a work setting and on a personal level. Those teams who implemented design review had an average of 4.4 whereas those that did not implement the design review process had an average of 4.1. This difference is likely due to the extra work that the design review members conducted with their peers to offer constructive criticism and effectively improve each other's individual contributions to the team's success.

In comparing the capstone design project teams that conducted design review with those that did not, the general trend was that the teams that conducted design review performed better than those teams that did not conduct design reviews. There were also only 3 teams that conducted design review during this study, compared to the 8 teams that did not implement a design review. Therefore, the results from the teams that implemented the design review process provide experimental results, while the results from the teams that did not implement the design review process provide the control.

\section{Conclusion and Way Forward}

This study focused mainly on three capstone design project teams over the course of one semester and the impact the design review process had on their teams. Specifically, this study tested the effect of the design review process on the following desired outcomes:

1) Enhanced learning opportunities for engineering students

2) Improve effectiveness of a team whose members are of different engineering subdisciplines

3) Improve the ability to communicate clearly and effectively with a range of audiences

4) Improve the ability to solve complex engineering problems

Ultimately, the design review process has a positive impact on all four areas examined in this study. It is recommended that a design review process be incorporated in project-based learning environments whenever possible to encourage students to review team members' work. This skill is critical to the success of all practicing civil engineers. 
Because civil engineering students composed the majority of the capstone design teams examined in this study, future studies should examine a variety of engineering disciplines (civil, mechanical, environmental, systems, etc.) or even non-engineering fields of study. A broader range of engineering disciplines will increase diversity and allow for the comparison of results between engineering disciplines. Future studies should also incorporate a greater number of participating teams to increase the statistical significance of the results. 


\section{References}

[1] Bruhl, J et al. "Mosul Dam - A Study in Complex Engineering Problems." ASEE's $123^{\text {rd }}$ Annual Conference and Exposition, 2016. https://peer.asee.org/mosul-dam-a-study-incomplex-engineering-problems.pdf.

[2] V. Giurgiutiu, A. E. Bayoumi, and G. Nall, "Mechatronics and smart structures: emerging engineering disciplines for the third millennium," Mechatronics, vol. 12, issue 2, 2002, pp. 169-181. [Online]. Available: https://doi.org/10.1016/S0957-4158(01)00057-5. [Accessed Dec. 7, 2020].

[3] A. T. Hill, "Student Mastery of Engineering with Design Review," Department of Civil \& Mechanical Engineering, U.S. Military Academy, 2018.

[4] Riemer, Marc. "Integrating Written Communication Skills in Engineering Education." University of Melbourne, 2002.

[5] Darling, Ann L and Dannels, Deanna P. "Practicing Engineers Talk About the Importance of Talk: A Report on the Role of Oral Communication in the Workplace." Communication Education, 2003, DOI: 10.1080/03634520302457.

[6] Brown, S et al. "BESTEAMS: Building Engineering Student Team Effectiveness and Management Systems." University of Maryland, The Catholic University of America, Morgan State University, United States Naval Academy, 2000, pp. 1-10.

[7] Carlson, P. A., et al. "Incorporating Student Peer-Review into an Introduction to Engineering Design Course." Proceedings Frontiers in Education 35th Annual Conference, 2005, pp. F2C-20. IEEE Xplore, doi:10.1109/FIE.2005.1612043.

[8] Frensch, Peter A, and Joachim Funke. Complex Problem Solving: The European Perspective. Psychology Press, 2014, Books.google.com, books.google.com/books?id=OZHAwAAQBAJ\&printsec $=$ frontcover\&source $=\mathrm{gbs} \_$atb $\# \mathrm{v}=$ onepage \&q\& $\mathrm{f}=$ false.

[9] Gehringer, Edward F. "Peer Grading Over the Web: Enhancing Education in Design Courses." North Carolina State University, 1998, pp 1-11.

[10] McAlpine, Iain, and Carl Reidsema. "The role of student peer review and assessment in an introductory project-based engineering design course." ConnectEd, International Conference of Design Education. 2007.

[11] CATME Smarter Teamwork, Purdue University, 2021, https://info.catme.org/.

[12] Iris Cushing, M.F.A. Assistance given to the authors, review of electronic work through the Mounger Writing Center. Ms. Cushing advised the authors on grammar and mechanics issues. Ms. Cushing noticed passive voice, comma, apostrophe, and subject-verb 
construction issues and provided resources that explain these grammatical rules and how to implement them. West Point, NY. 22 February 2021. 


\section{$\underline{\text { Design Review }}$}

Follow Steps 1-8:

1. Identify and confirm your "role" or "job" within your team (e.g., Project Manager, Fabrication Specialist, Lead Cellular Wall Designer).

2. Partner up with a teammate. This teammate will be your Reviewer and you will be their Reviewer. Ensure you and your partner can effectively review each other's work given both of your academic majors.

3. Think about your partner's role on the team. What are they working on? What should they know about the project? Come up with a set of questions (at least 5) to ask your partner that would provide you with an in-depth analysis of their role. Write these questions on Page 2. Have your questions approved by your instructor/advisor.

4. Give your partner your current products in a form that best showcases your work so far on the project (e.g., Excel, typed summary, SolidWorks, MS Project). The products should be complete and easy to follow for your Reviewer.

5. After you receive your partner's products, independently conduct a design review of their work (This Step must be conducted by yourself and you may not contact your partner in any way). Attempt to thoroughly answer each of the questions you wrote in Step 3. If you cannot answer a question, articulate this next to the question on Page 2. If you are unsure of or confused about something in their work, comment about it on Page 3. Provide any recommendations you have about their work on Page 3.

6. After you and your partner are complete with your design reviews, sit down and discuss each other's reviews. Discuss any unanswered questions and clarify any points of confusion or recommendations with your partner.

7. On Page 3 of your partner's design review, respond to the questions, comments, concerns, and recommendations that they had for you. Adjust your initial product based on your partner's design review. Keep the design review your partner completed.

8. Submit/present the design reviews based on your instructor's/advisor's guidance. 
Designer Name/Team Role:

Reviewer Name/Team Role:

Date/Time Step 4 Completed:

\section{Reviewer Questions for the Designer (include Answers):}

1.

2.

3.

4.

5 .

6.

7.

8. 
APPENDIX

Reviewer Comments / Recommendations:

Date/Time Step 5 Completed:

\section{Designer Response:}

Designer Signature/Date:

Reviewer Signature/Date: 
